EDITORIAL

Rev Chil Salud Pública 2020, Vol 24(2): $83-85$

\title{
LA TOTALIDAD ESQUIVA; REQUISITOS PARA UN ANÁLISIS
}

THE EVASIVE TOTALITY: REQUIREMENTS FOR ANALYSIS

Los conceptos tienen consecuencias. Que la salud tiene que ver con la sociedad en que ocurre, es algo que se ha sostenido desde siempre. Sin embargo, algo hay en la forma como se ha conceptualizado este punto, que siempre el mundo social no ha pasado de ser un factor, una dimensión, una arista (o una pizca, para los que no creen mucho en la promesa de las ciencias sociales), pero se ha perdido -y quizás para siempre (o quizás siempre ha estado perdida)- la concepción de salud y sociedad como un todo, algo que la pandemia subraya constantemente.

El punto es muy importante y requeriría un análisis detallado acerca de como se desarrolló esta conceptualización. Un ejemplo de lo que estoy pensando está contenido en el artículo de Emilio Quevedo y Claudia Cortés "El concepto de 'sistema': de la química y la fisiología a la salud pública y las ciencias sociales. Bases para una investigación futura"1. En este texto, los autores dejan en claro cómo los conceptos fisiológicos traspasan las barreras disciplinares -otro tipo de spillover-, cómo se produce la 'naturalización' de la sociedad y, en síntesis, cómo se genera el funcionalismo, corriente dominante en las ciencias sociales de los años sesenta del siglo pasado, en el que son fundamentales conceptos como 'homeostasis' y 'regulación'. Analizando los escritos y los cursos que daban el bioquímico Laurence J. Henderson y el fisiólogo Walter B. Cannon en las primeras décadas del siglo XX, se entiende claramente lo bien que pueden calzar estos análisis sociológicos con los estudios de medicina².

Aunque suene algo paradojal, esa noción de sistema favorece la concepción de 'lo social' como una parte, dimensión, o arista de lo que esté en análisis. Hay partes y hay un todo, pero el análisis tiende a privilegiar solo el funcionamiento de la parte para el conjunto. Que quede, por ahora, como un posible tema de reflexión e indagación, pero no hay que desentenderse del punto, sobre todo si consideramos que campos tan importantes como los famosos y recurrentes determinantes sociales en salud también pueden estar teñidos con él.

Para un cientista social, la pandemia es un circo de mucho más de tres pistas. Es una entretención permanente, si no fuera por sus dramáticas consecuencias.

Para donde uno mire, lo que se aprecia es el funcionamiento integrado del mundo. En cualquier punto que uno quiera detenerse, se ve de inmediato como el mundo -como un paño sin costuras- muestra la urdimbre de que está hecho. Como la luz, puede descomponerse en diversos haces de frecuencia que, refractados, podrá dar la ilusión de un color puro y distinto, pero en el fondo uno está viendo siempre el haz completo. La gracia está en que podamos analíticamente apreciar el abigarrado conjunto.

Tratándose además de una enfermedad infecciosa y con particulares vías y contextos de infección, el COVID 19 es expresión de relaciones sociales. Como lo planteara un antropólogo venezolano, es un hecho indiscutible que: "...estos microorganismos no caminan por sí solos, caminan con nosotros; de allí que todo proceso de contagio es un proceso social y es un proceso histórico. Tenemos que entender a los contagios a partir de relaciones sociales, a partir de la forma en que interactuamos los seres humanos"3.

Siguiendo esa sensata observación, pueden hacerse varias preguntas: ¿Lugar de entrada del virus a Chile? Sectores acomodados del país; ellos son los que viajan al sudeste asiático o a Milán o a Madrid. ¿Formas de diseminación del virus? Nadie fun-

Jorge Gaete Editor Asociado Revista Chilena de Salud Pública ciona solo en este mundo. Ni los sectores acomodados; allí hay servicio doméstico, jardineros, vigilantes, dependientes de comercio... Estas personas viven en otras comunas de la ciudad (comunas dormitorio) donde se vive de otra manera. En esas co- 
munas hay hacinamiento, menos espacio para todo y para todos. El aire no está libre, está encajonado entre calles estrechas y pasajes y el contagio es una realidad palpable. ¿Posibilidades de cumplir con el confinamiento? El teletrabajo de los mayores y la escolaridad de los chicos no siempre es posible: se necesita computador y una buena conexión a internet.

¿Y en qué está la protección social? Las licencias médicas existen para compensar las pérdidas de ingresos debido a enfermedades o accidentes. Igual ocurre con los seguros de cesantía. Sin embargo, el funcionamiento de estos mecanismos depende del carácter formal o informal de la ocupación. En el año 2018 el 29\% de la fuerza de trabajo estaba comprometida con el sector informal, y esto evidentemente varía según los recursos económicos de la población: en el quintil más pobre de nuestra economía el porcentaje de la fuerza de trabajo ocupada en el sector informal ascendía al 72\%: casi tres cuartas partes de esa población sobrevive vendiendo quincallería en las cunetas.

Pero el funcionamiento integrado del mundo no se expresa sólo en estos aspectos de la exposición diferencial al riesgo según ingresos, recursos o calidad de vida. El entramado de la vida social y económica es tan denso que hoy una crisis sanitaria incide poderosamente en la vida política de la nación. Es tan intrincada esta trama que hoy es posible que un dirigente empresarial se pregunte acerca de quien tiene las llaves de la economía: ¿el ministro de salud o el ministro de hacienda o economía? Y que el mismo dirigente proponga "... lograr el justo medio entre lo sanitario y lo económico." La trama es intrincada pero también tan difusa que, días después de estas declaraciones, un infectólogo de una universidad del sur indicaba "... estamos en el surgimiento de una segunda ola, y las medidas de control epidemiológico en Chile han sido relajadas, no por mejoría epidemiológica, sino por una sopreposición de la parte económica... Pareciera que Trump o Bolsonaro estuvieran gobernando el país."

Destacando esta apretada urdimbre, y vinculando sociedad, economía y política, el presidente del Banco Central de Chile Mario Marcel explicaba: "Desde octubre de 2019, la economía chilena ha sufrido tres shocks superpuestos: la crisis social, las crisis sanitaria local, y el impacto de la crisis sanitaria global. Estos tres shocks son inéditos por su origen no económico, su superposición temporal y su impacto sobre variables similares" ${ }^{\prime \prime}$.

¿Existe algo así como 'un justo medio entre lo sa- nitario y lo económico' como lo reclamaba el dirigente empresarial? Si es que existe, parece un punto muy difícil de determinar. Pero, más allá de esta hipotética suposición, lo que yo quisiera destacar es que dirigente, epidemiólogo sureño y presidente del Banco Central -los tres emisores de discursos- están concientes de que economía y salud están tremendamente vinculadas. Esta vinculación siempre ha existido, siempre ha estado detrás de cómo las cosas ocurren y de por qué ocurren de esa y no de otra manera. $Y$ es esta pandemia la que, como tantas otras situaciones, la pone en evidencia.

"Es evidente que nuestra vida intelectual está muy mal hecha" dice Bruno Latour ${ }^{5}$. La trama de la realidad es intrincada, pero puede y debe serlo aun más. Nuestras formas de conocer están mal planteadas y, por lo habitual, no logran hacer justicia a la complejidad del mundo. Siguiendo con Latour, es claro que al menos debiéramos sortear la primera división: la que separa el conocimiento de las cosas, del interés, el poder y la política de los hombres. Por un lado están las cosas (la pandemia, por ejemplo) y por otro las palabras para referirnos a ellas. Quiero decir que la realidad de la pandemia es algo concreto (aun cuando ese 'concreto' fácilmente se diluye cuando se escarba un poco en las operaciones conceptuales para precisarlo, como todo lo sólido se desvanece en el aire), y otra situación es el relato que da cuenta de ella. Estos relatos se emiten desde lugares específicos y determinados históricamente y allí es donde se conjugan intereses y concepciones y se perfilan por consiguiente líneas de acción. Obviamente, un lugar específico es el Ministerio de Salud, otro es el Colegio Médico y otros los departamentos de Salud Pública de las universidades nacionales.

Así, retomando las opiniones comentadas recién, quien considera que hay que recuperar la llave de la economía es un personero de la derecha habitualmente tendiente a favorecer la economía; quien considera que se está protegiendo en demasía la actividad económica es un académico sin mayores responsabilidades en el mundo.

En otro plano figurado, están las cosas de hoy, y más allá o más atrás, las cosas de ayer. Cierto es que de algún modo todo es presente: es presente el cólera de 1880, la gripe española de 1918, la gripe asiática de 1958, la gripe aviar de 2009... Están presentes en la medida que son experiencias asumidas y referentes, en algun grado, para la evaluación de la situación actual.

Por ejemplo, entre 1880 y 1890 el cólera y la vi- 
ruela asolaban Santiago. La Sociedad Médica de Santiago expresaba su preocupación y destacaba como las condiciones sanitarias de entonces favorecían los contagios y sus consecuencias. "Ya han transcurrido muchos días que penetró en nuestro territorio, -dirá uno de los médicos de entonces- $i^{i}$ qué hemos adelantado en condiciones higiénicas? ... nuestros viejos conventillos siguen inmundos, sus moradores continúan viviendo revueltos con sus desperdicios; nuestro pésimo sistema de desague, sus acequias siguen desbordándose y cuando el cólera haya penetrado a la ciudad, las acequias se encargarán de llevar el contagio hasta la puerta misma de los hogares..." 6 . Hay evidentes diferencias con la situación actual, pero al igual que hoy las condiciones sociales de vida era lo que incidía fundamentalmente en la situación.

Cansados, los médicos insistían en la necesidad de introducir cambios profundos en las formas de vida: "Ha sonado la hora de una reforma radical y seria en nuestro modo de ser social, con relación a la salubridad pública".

¿Una reforma seria de nuestro ser social? En ese entonces, la elite profesional se preocupó en gran medida por la situación. De esto da detallada y personal cuenta Carlos Molina ${ }^{7}$. Sin embargo, y aun cuando faltan años para que se produzca una vacuna efectiva contra la viruela, esa elite médica depositará toda la confianza en la vacuna, y la 'reforma radical y seria de nuestro modo de ser social' quedará para un futuro indefinido.

Hoy estamos con una nueva Constitución en ciernes: tenemos ciertamente la posibilidad de una reforma seria de nuestro ser social... Sin embargo, y viendo los caminos por donde vamos, pareciera que, una vez más, el pensamiento biomédico se impondrá y la solución buscada será entonces la vacuna. Hoy estamos en una idéntica situación. Y una vez más será la vacuna la que resolverá el entuerto. La vacuna es la bala de plata de la biomedicina: permite resolver la crisis sin que sea necesario alterar nuestro medio social. Corremos una vez más el riesgo de que la vacuna sea asumida como la nueva panacea y anule, oscureciéndolo, todo el panorama que hoy vemos con claridad.

Es muy posible que esto ocurra. Tal como en las anteriores experiencias, es posible que nuestra inmunidad sea ajustada y el virus no afecte ya nuestra capacidad respiratoria. Si eso llega a ocurrir y el mundo sigue indemne, ¿cómo es posible que algo así pase? ¿Las profesiones son un marco de hierro, que limita las actuaciones profesionales en ámbitos determinados? ¿Esperar que las profesiones de la salud logren algo más será como pedirle peras al olmo?

Digamos para terminar, y una vez más, que todo lo descrito existía desde siempre, y por supuesto desde antes del coronavirus...

\section{REFERENCIAS BIBLIOGRÁFICAS}

1. Emilio Quevedo, Claudia Cortés. El concepto de 'sistema': de la química y la fisiología a la salud pública y las ciencias sociales. Bases para una investigación futura, Revista Ciencias de la Salud 2015; 13 (esp): 105-125.

2. A estos cursos asistían sociólogos importantes como Robert Merton y Talcott Parsons, este último autor entre otras obras de un análisis de la relación médico-paciente como 'sistema social'. A mediados de los sesenta, Juan César García -que en esos momentos está en vías de ser el Juan César que se consagrará años después- dará unas charlas a médicos jóvenes de la Universidad de Chile. Uno de ellos, amigo mío desde esos años, me señaló en diversas ocasiones lo muy útil que resultó para él entender la idea del sistema social: el hospital como un sistema social, la relación médico-paciente como un sistema social, la escuela de medicina como un sistema social.

3. "Pandemias, la perspectiva de la historia", con Inés Quinteros y Rogelio Altez. 23 de junio de 2020 https:// www.youtube.com/watch? $v=T c m t 3 z 96 b 44 \& t=3273 \mathrm{~s}$ (acceso el 13 noviembre 2020)

4. Mario Marcel, La economía chilena frente al COVID-19: fortalezas, desafíos y riesgos. Seminario Visión Económica 2021, SOFOFA-UDD, Santiago 18 de diciembre 2020. Seminario0

5. Bruno Latour. Nunca fuimos modernos. Ensayo de antropología simétrica. Siglo Veintiuno Editores, Buenos Aires 2007

6. Nunca he podido mantener ordenadas las referencias bibliográficas en mis trabajos. En mis viejos apuntes tengo registrado un artículo del Dr. Isaac Ugarte "Cólera y viruela en Chile" publicado en la Revista Médica de Chile de septiembre de 1883. Desgraciadamente, la pandemia me impide ser más riguroso en esta referencia.

7. Carlos Molina Bustos. La cuestion social y la opinión de la elite médica 1880-1890. Anales de la Historia de la Medicina, Año XVI, 1, 2006. 